\title{
BMJ Open Predictors of emergency department use by adolescents and adults with autism spectrum disorder: a prospective cohort study
}

\author{
Yona Lunsky, ${ }^{1,2}$ Jonathan A Weiss, ${ }^{3}$ Melissa Paquette-Smith, ${ }^{4}$ Anna Durbin,,${ }^{1,2,5}$ \\ Ami Tint, ${ }^{1,3}$ Anna M Palucka, ${ }^{1,2}$ Elspeth Bradley ${ }^{2}$
}

To cite: Lunsky Y, Weiss JA, Paquette-Smith $\mathrm{M}$, et al. Predictors of emergency department use by adolescents and adults with autism spectrum disorder: a prospective cohort study. BMJ Open 2017;7:e017377. doi:10.1136/ bmjopen-2017-017377

- Prepublication history for this paper is available online. To view these files, please visit the journal online (http://dx.doi. org/10.1136/bmjopen-2017017377).

Received 19 April 2017 Revised 15 May 2017

Accepted 19 May 2017

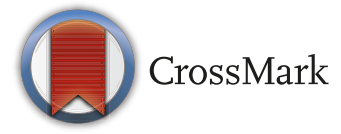

${ }^{1}$ Centre for Addiction and Mental Health, Toronto, Canada

${ }^{2}$ Department of Psychiatry, University of Toronto, Toronto, Canada

${ }^{3}$ Department of Psychology, York University, Toronto, Canada ${ }^{4}$ Department of Psychology, University of Toronto Mississauga, Mississauga, Ontario, Canada

${ }^{5}$ Research and Evaluation, Canadian Mental Health Association-Toronto Branch, Toronto, Canada

Correspondence to

Dr Yona Lunsky; yona.lunsky@ camh.ca

\section{ABSTRACT}

Objectives To determine predictors of emergency department (ED) visits in a cohort of adolescents and adults with autism spectrum disorder (ASD).

Design Prospective cohort study.

Setting Community-based study from Ontario, Canada. Participants Parents reported on their adult sons and daughters with ASD living in the community $(n=284)$. Main outcome measures ED visits for any reason, ED visits for medical reasons and ED visits for psychiatric reasons over 1 year.

Results Among individuals with ASD, those with ED visits for any reason were reported to have greater family distress at baseline $(p<0.01)$, a history of visiting the ED during the year prior $(p<0.01)$ and experienced two or more negative life events at baseline $(p<0.05)$ as compared with those who did not visit the ED. Unique predictors of medical versus psychiatric ED visits emerged. Low neighbourhood income $(p<0.01)$ and living in a rural neighbourhood $(p<0.05)$ were associated with medical but not psychiatric ED visits, whereas a history of aggression $(p<0.05)$ as well as being from an immigrant family $(p<0.05)$ predicted psychiatric but not medical emergencies.

Conclusions A combination of individual and contextual variables may be important for targeting preventative community-based supports for individuals with ASD and their families. In particular, attention should be paid to how caregiver supports, integrative crisis planning and community-based services may assist in preventing or minimising ED use for this vulnerable population.

\section{INTRODUCTION}

Across childhood, adolescence and adulthood, individuals with autism spectrum disorder (ASD) are more likely to visit the emergency department (ED) than their typically developing peers for both medical and psychiatric reasons. ${ }^{1-6}$ The high-intensity environment of an ED visit can be extremely challenging for individuals with ASD, who may present with sensory, social communication and behavioural difficulties. ${ }^{7}$ Perhaps representative of these challenges,

\section{Strengths and limitations of this study}

- This is one of the first published studies to date to compare the profiles of individuals with autism spectrum disorder who did and did not visit the emergency department.

- A convenience sample in a setting with universal health insurance was used and may be limited in its generalisability.

- Data were based on parent self-report rather than on chart abstraction and so may be susceptible to biases.

individuals with ASD are restrained or sedated in approximately one in four ED visits. $^{8}$ ASD knowledge gaps and inadequate professional training often compound these negative experiences for affected individuals and their family caregivers. ${ }^{9} 10$ From a systemic perspective, frequent ED use is costly and ED overcrowding and long wait times are key system level challenges in most jurisdictions. ${ }^{11} 12$ The number of ED visits by individuals with ASD is increasing, ${ }^{5}$ and it is important to better understand predictors of ED visits among individuals with ASD to assist in appropriate provision of community-based care.

Individuals with ASD often have complex care needs and can visit the ED for a host of psychiatric and medical concerns. In addition to an increased risk of developing co-occurring mental health concerns such as anxiety and depression, ${ }^{13} 14$ youth and adults with ASD often display problem behaviours, including elopement, aggression and selfharming behaviours, ${ }^{15-17}$ which frequently necessitate emergency care. ${ }^{2} 38$ Gastrointestinal issues (eg, abdominal pain, nausea and vomiting) and neurological symptoms and disorders (eg, seizures and epilepsy) are common comorbid medical concerns among 
individuals with ASD and account for a large proportion of medical related ED visits in this population. ${ }^{12} 51819$ Youth with ASD may also be at high risk for ED visits due to accidents and injury. ${ }^{20-22}$ Medical issues can be further complicated by atypical clinical presentations, such that problem behaviours can sometimes mask underlying medical conditions. ${ }^{23} 24$

In recent years, several studies have compared ED patterns in those with and without $\mathrm{ASD}^{1-6}$; however, we know very little about what differentiates individuals with ASD who use the ED compared with those with ASD who do not use the ED. Additionally, the majority of what is known about emergency service use patterns in individuals with ASD comes from the analysis of administrative data. This type of analysis is limited in its ability to describe situational and family centred variables that are not typically documented in insurance claims or medical records. Our previous retrospective, cross-sectional study on $\mathrm{ED}$ use in $\mathrm{ASD}^{8}$ demonstrated that factors such as previous ED visits, lack of meaningful day time activities and a history of hurting others were related to emergency service use, whereas demographic variables were not. This study, however, was limited in that it did not explore how these variables impact ED use over a longer period of time.

The current study investigates predictors of ED use in adolescents and adults with ASD based on parent reported data. As a secondary exploratory aim, we sought to separately examine predictors of medically related ED visits and predictors of psychiatric related ED visits to determine if they were distinct. For these analyses, a modified version of Andersen's Behavioural Model of Health Services Use ${ }^{25}$ was used to group predictors into three categories: (1) predisposing factors (ie, static demographic characteristics that describe the likelihood an individual will seek healthcare in a given situation), (2) enabling factors (ie, environmental characteristics and available resources) and (3) need variables (ie, events or medical/psychological conditions that might facilitate a greater need for services).

\section{METHODS \\ Participants}

Parents of adolescents and adults with ASD age 12 years and up were recruited from across Ontario, Canada, between December 2010 and October 2012. Parents were recruited from flyers and websites of collaborating community agencies, recreation programs and schools that support individuals with ASD, as well as through every local chapter of the provincial ASD organisation. To be eligible for the study, individuals with ASD needed (1) to be living in Ontario, (2) to be 12 years of age or older, (3) to have a clinical diagnosis of ASD and (4) to exceed the recommended cut-off score of 12 on the Social Communication Questionnaire-Lifetime Version (SCQ), ${ }^{26}{ }^{27}$ a standardised ASD screening tool. A total of 514 families consented to participate in the study and 462 completed the baseline survey; 396 of these participants met the age and SCQ cut-offs. Families were contacted every 2 months to report on their ED use and were contacted approximately 1 year after baseline to fill out a final survey. To be included in the current study, parents were required to complete the final survey within 18 months of their baseline date. The final sample for the current study consisted of 284 individuals with ASD (mean age 18.41 years, SD 6.16; 223 males, 61 females). There were no significant differences between the final sample $(n=284)$ and those who did not complete the final survey within the required time period $(n=112)$ with respect to most individual and parent demographics (individual age, individual gender, individual place of residence, parent age, parent marital status, parent education and neighbourhood income) or clinical needs (individual ASD severity, individual ID status, individual medical and psychiatric diagnoses; all $\mathrm{p}>0.05$ ). However, a significantly greater proportion of non-responders identified as non-Caucasian $(26.6 \%$ vs $17.0 \%, \mathrm{p}=0.03$ ).

The majority of survey respondents were mothers $(93.7 \%)$, and nearly half reported that their dependent with ASD was 18 years or older (44.7\%). Most individuals with ASD lived with family (91.2\%) at the time of baseline survey completion, and the remaining were reported to reside in group homes or other supported living situations $(6.4 \%)$, in treatment facilities $(0.7 \%)$ or independently $(1.8 \%)$.

\section{Measures}

\section{Predictor variables}

All predictor variables were collected as part of the baseline survey.

\section{Predisposing variables}

Individual predisposing variables included age, gender, intellectual disability (ID) status and ASD severity. ID status was split into those who had an ID (ie, mild to profound ID) and those who did not (ie, gifted, normal and borderline intelligence). ASD severity was measured using the $\mathrm{SCQ}^{26}$ with higher scores reflective of more severe symptomology. The SCQ is reported to have good internal consistency (alpha coefficients 0.81-0.93); and external validity. ${ }^{27}$ In the current study, internal consistency for the overall scale was strong (Cronbach's alpha $=0.81$ ).

\section{Enabling variables}

Parent enabling variables included marital status (married/living with partner or single), education level and if they were born in Canada (yes/no). Parent education level was dichotomised into high education (college diploma or higher) or low education (some college or university education or lower). Household income of each family was estimated based on the median income of the respondent's postal code region according to census data $^{28}$ (range \$33030.00-\$107742.00, mean \$65597.12, SD \$15970.27). Since the neighbourhood income in our sample was higher than the national mean (\$53634), we 
compared families whose neighbourhood income fell into the bottom quartile with those that fell in the top three quartiles of our sample. Postal codes were also used to determine rural status (rural vs urban) based on Statistics Canada's definition of rurality. ${ }^{29}$ Individuals were classified as either having or not having 'structured' daytime activities based on parents' responses to the question "What does your child do during his/her typical day? (ie, school, working, volunteering or job training, day programme, no structured daytime activity or other)". Family distress was measured at baseline using the 10-point Brief Family Distress Scale, ${ }^{30}$ which asks parents to indicate their level of distress on a scale from 1 'everything is fine we are not in crisis at all' to 10 'we are currently in crisis, and it could not get any worse'.

\section{Need variables}

Parents were asked to provide current medical (eg, gastrointestinal and skin conditions) and psychiatric diagnoses (eg, anxiety and depression) for their child with ASD. Comorbid medical and psychiatric diagnoses were each dichotomised as has been done in many largescale parent report surveys. ${ }^{31} 32$ Parents indicated (yes/ no) whether their child had a history of aggression and whether they visited the ED in the year prior to the baseline survey.

Parents also completed a modified version of the negative life events checklist from the Psychiatric Assessment for Adults with Developmental Disabilities Checklist $\left(\right.$ PAS-ADD ${ }^{33}$ ), in which they were to check off any of the significant life events that their child experienced in the 2 months prior to baseline (eg, death of a family member, change in residence and loss of a job). For this analysis, the 'injury to self' item was excluded as injuries may directly cause an ED visit. The checklist was dichotomised into individuals who had two or more negative life events prior to beginning the survey and those who had fewer than two, similar to past studies using this measure. ${ }^{345}$

\section{Dependent variables}

\section{Primary outcome variable (ED visit)}

In each of the follow-up surveys, parents were asked to indicate (yes/no) whether their child used the ED in the last 2 months. Parents were also asked in the final survey about whether their child had any ED visits in the previous year. Individuals with ASD were dichotomised into individuals with and without any ED visit during the past year. To ensure that the sampling period for visits was standardised across participants, only ED visits during the year that preceded participants' final survey were included. All participants were therefore sampled for 12 months.

\section{Secondary outcome variables (medical or psychiatric ED visits)}

Parent descriptions of visits were coded independently by two authors (MP-S and AT) as being either medical or psychiatric in nature with $98 \%$ inter-rater agreement. Any disagreements were resolved through discussion with the senior author (YL). If parents provided detailed descriptions of more than one ED visit, each visit was coded separately. Thus, the same individual could be classified as having both a medical emergency and a psychiatric emergency $(n=3)$. Some parents failed to provide enough descriptive information about emergencies in their bimonthly form for these emergencies to be coded $(n=17)$, so these cases were excluded from the secondary analysis of emergency type.

\section{PROCEDURE}

The York University and Centre for Addiction and Mental Health research ethics boards approved this research. Consenting parents were sent their baseline survey electronically or on paper. The majority of participants $(\mathrm{n}=223 ; 78.5 \%)$ completed online surveys. Parents who completed the surveys online (mean 48.67 years, SD 6.88) were significantly younger than parents who completed the surveys via mail or telephone interview $(n=61$; mean 52.36 years, SD 8.44, $\mathrm{p}=0.001$ ); no other parent or individual demographic variables differed according to survey response method. Participants had a unique identifier that was linked to their information, and every 2 months following the completion of their last survey, they received another follow-up survey. At their final time point, they received a longer measure to complete. Participants received payment (\$20) on completing baseline information and subsequent payment (\$20) when they completed their final measure.

\section{Data analysis}

A bivariate analysis compared the groups with and without ED visits using single predictor logistic regression models. From these models, we derived ORs to demonstrate the relationship between each predictor variable and the likelihood of having any ED use. To identify the relative influence of these variables, we then ran two adjusted logistic regression explanatory models predicting any ED use. The first included all the variables that had a $p$ value of 0.20 or lower in the bivariate analysis, as well as the age variable that did not meet this threshold but was included since it is a potential confounder. The second adjusted logistic regression model included all predictor variables.

Subsequently, we examined if different variables were associated with medical ED visits compared with psychiatric ED visits. To do this, we again ran single predictor logistic regression models on two different subsets of the sample. First, these models were used to compare individuals with any medical ED visits with individuals with no medical ED visits. Second, we used these models to compare individuals with any psychiatric ED use relative to individuals with no psychiatric ED use. Adjusted logistic regressions could not be conducted as part of this analysis due to the small number who presented with each type of visit.

For all of the models, individuals with missing data for ID status $(n=31)$ were included, but individuals with 
missing data for parental education $(n=2)$ were excluded since it was not sufficiently large to be included as its own category. Analyses were conducted using SPSS version 24.

\section{RESULTS}

\section{ED use}

Of the cohort of 284 individuals, 63 (22.2\%) reported ED use during the year following their baseline data collection and $221(77.8 \%)$ reported no ED use during that year. Participant demographic and clinical characteristics according to ED outcome are shown in table 1.

In the bivariate analysis, higher family distress, living in a rural area, being on medication, having an ED visit in the past year and having two or more negative life events were significant at the 0.05 level. In addition, gender, neighbourhood income, daytime activity and psychiatric comorbidity had $\mathrm{p}$ values larger than 0.05 but less than 0.20 (table 2). Despite the two adjusted models, including different predictors (the first included predictors with a $p$ value of less than 0.20 in the bivariate analysis, and the second model included all predictor variables), both models yielded similar results. In both models, clinical need variables (having an ED visit in the year prior to the study and reporting two or more significant life events at baseline) and one enabling variable (family distress) predicted having any ED use, when controlling for other variables (see table 2).

\section{Medical and psychiatric ED visits}

Forty-six of the 63 parents who reported that their child visited the ED provided a detailed description of at least one such visit. Three parents described separate psychiatric and medical visits. For the purposes of the following analyses, we included only the first medical and the first psychiatric visit described by each parent for a total of 49 descriptions of ED visits. Of the 49 described ED visits, 31 visits related to medical issues and 18 visits related to psychiatric issues. The most common type of medical visit was injury $(\mathrm{n}=10)$, followed by gastrointestinal issues $(\mathrm{n}=4)$ and infections $(\mathrm{n}=4)$. The most common reason for psychiatric ED visits was related to self-harm and/ or suicidality $(\mathrm{n}=5)$ followed by physical assault towards family members $(n=3)$ and three incidents where parents described individuals as both a danger to self and others.

As shown in table 3, bivariate analyses indicate that medical ED visits were associated with living in a lower-income neighbourhood, living in a rural area and family distress at baseline (enabling factors), along with two or more negative life events, being on medication at baseline and visiting the ED in the year prior to data collection (need factors). Two enabling factors (parent immigrant status and family distress) predicted having a psychiatric ED visit in the follow-up period (see table 3). Clinical need variables, such as being on medication, having a history of aggression and having two or more negative life events were also significantly associated with psychiatric emergencies.
Table 1 Demographic and clinical characteristics of 284 youth and adults with ASD living in Ontario with and without ED visits

\begin{tabular}{llll}
\hline $\begin{array}{l}\text { Total sample } \\
(\mathrm{N}=284)\end{array}$ & $\begin{array}{l}\text { Visited ED } \\
(\mathrm{n}=63)\end{array}$ & $\begin{array}{l}\text { Did not visit } \\
\text { ED ( } \mathrm{n}=221)\end{array}$ \\
\hline $\mathrm{n}(\%)$ & $\mathrm{n}(\%)$ & $\mathrm{n}(\%)$
\end{tabular}

\begin{tabular}{|c|c|c|c|}
\hline \multicolumn{4}{|l|}{ Predisposing } \\
\hline \multicolumn{4}{|l|}{ Age } \\
\hline Mean (SD) & $18.4(6.2)$ & $18.8(5.9)$ & $18.3(6.3)$ \\
\hline \multicolumn{4}{|l|}{ Gender } \\
\hline Female & 61 (21.5) & 19 (30.2) & 42 (19.0) \\
\hline Male & $223(78.5)$ & $44(69.8)$ & $179(81.0)$ \\
\hline \multicolumn{4}{|l|}{ SCQ score } \\
\hline Mean (SD) & $22.6(6.3)$ & $22.5(6.7)$ & $22.6(6.2)$ \\
\hline \multicolumn{4}{|l|}{ ID } \\
\hline ID & $132(46.5)$ & $29(46.0)$ & $103(46.6)$ \\
\hline No ID & $121(42.6)$ & $30(47.6)$ & 91 (41.2) \\
\hline Missing & 31 (10.9) & $4(6.3)$ & 27 (12.2) \\
\hline
\end{tabular}

Parent marital

status

\begin{tabular}{|c|c|c|c|}
\hline Unmarried & $67(23.6)$ & $18(28.6)$ & $49(22.2)$ \\
\hline $\begin{array}{l}\text { Married/living } \\
\text { with partner }\end{array}$ & $217(76.4)$ & $45(71.4)$ & $172(77.8)$ \\
\hline \multicolumn{4}{|l|}{ Parent immigrated } \\
\hline Yes & $67(23.6)$ & $15(23.8)$ & $52(23.5)$ \\
\hline No & $217(76.4)$ & 48 (76.2) & $169(76.5)$ \\
\hline \multicolumn{4}{|l|}{ Parental education } \\
\hline High education & $211(74.3)$ & 48 (76.2) & $163(73.8)$ \\
\hline Low education & $71(25.0)$ & $56(23.8)$ & $56(25.3)$ \\
\hline Missing & $2(0.7)$ & 0 & $2(0.9)$ \\
\hline \multicolumn{4}{|l|}{$\begin{array}{l}\text { Neighbourhood } \\
\text { income }\end{array}$} \\
\hline Low & $59(20.8)$ & $18(28.6)$ & $41(18.6)$ \\
\hline High & $225(79.2)$ & 45 (71.4) & $180(81.4)$ \\
\hline \multicolumn{4}{|l|}{ Daytime activity } \\
\hline Unstructured & $39(13.7)$ & $13(20.6)$ & $26(11.8)$ \\
\hline Structured & $245(86.3)$ & $50(79.4)$ & $195(88.2)$ \\
\hline \multicolumn{4}{|l|}{ Family distress } \\
\hline Mean (SD) & $4.2(1.8)$ & $5.0(1.9)$ & $3.9(1.7)$ \\
\hline \multicolumn{4}{|l|}{$\begin{array}{l}\text { Urban-rural } \\
\text { residence }\end{array}$} \\
\hline Urban & $254(89.4)$ & $52(82.5)$ & $202(91.4)$ \\
\hline Rural & $30(10.5)$ & $11(17.5)$ & $19(8.6)$ \\
\hline \multicolumn{4}{|l|}{ Need } \\
\hline \multicolumn{4}{|l|}{$\begin{array}{l}\text { Medical } \\
\text { comorbidity }\end{array}$} \\
\hline Yes & $98(34.5)$ & $23(36.5)$ & $75(33.9)$ \\
\hline No & $186(65.5)$ & $40(63.5)$ & $146(66.1)$ \\
\hline \multicolumn{4}{|l|}{$\begin{array}{l}\text { Psychiatric } \\
\text { comorbidity }\end{array}$} \\
\hline Yes & $132(46.5)$ & $36(57.1)$ & $96(43.4)$ \\
\hline
\end{tabular}

Continued 


\begin{tabular}{|c|c|c|c|}
\hline & $\begin{array}{l}\text { Total sample } \\
(\mathrm{N}=\mathbf{2 8 4})\end{array}$ & $\begin{array}{l}\text { Visited ED } \\
(n=63)\end{array}$ & $\begin{array}{l}\text { Did not visit } \\
\text { ED }(n=221)\end{array}$ \\
\hline & n (\%) & n (\%) & n (\%) \\
\hline No & $152(53.5)$ & 27 (42.9) & $125(56.6)$ \\
\hline \multicolumn{4}{|c|}{ On medication } \\
\hline Yes & $162(57.0)$ & $46(73.0)$ & $116(52.5)$ \\
\hline No & $122(43.0)$ & $17(27.0)$ & 105 (47.5) \\
\hline \multicolumn{4}{|c|}{$\begin{array}{l}\text { History of } \\
\text { aggression }\end{array}$} \\
\hline Yes & $180(63.4)$ & $42(66.7)$ & $138(62.4)$ \\
\hline No & $104(36.6)$ & 21 (33.3) & 83 (37.6) \\
\hline \multicolumn{4}{|c|}{$\begin{array}{l}\text { ED visit in past } \\
\text { year }\end{array}$} \\
\hline Yes & 67 (23.6) & $30(47.6)$ & 37 (16.7) \\
\hline No & 217 (76.2) & $33(52.4)$ & $184(83.3)$ \\
\hline \multicolumn{4}{|c|}{$\begin{array}{l}2+\text { Negative life } \\
\text { events }\end{array}$} \\
\hline Yes & 68 (23.9) & 26 (41.3) & $42(19.0)$ \\
\hline No & 216 (76.9) & 37 (58.7) & 179 (81.0) \\
\hline
\end{tabular}

ASD, autism spectrum disorder; ED, emergency department; ID, intellectual disability; SCQ, Social Communication Questionnaire.

\section{DISCUSSION}

\section{Principal findings}

Approximately 22\% of individuals with ASD went to the $\mathrm{ED}$ at least once in a 12-month period. The results suggest that a combination of enabling (family distress) and need variables (visiting the ED in the year prior and having two or more negative life events at baseline) predicted ED use. In the secondary analysis, family distress, life events and being on medication were associated with having both medical and psychiatric emergencies at the bivariate level. Interestingly, low income and living in a rural area were associated with medical but not psychiatric emergencies. Conversely, having a history of aggression, as well as being from an immigrant family, predicted psychiatric but not medical emergencies.

\section{Strengths and limitations}

This is the first study to examine ED visits in adolescents and adults with ASD prospectively based on families' reports. Other studies have focused primarily on emergencies in children and youth with ASD without including both family and individual variables. We examined how a wide range of predisposing, enabling and need factors contributed to ED use in this population. We also identified unique contributors to medical and to psychiatric emergencies, although our sample size did not allow for these results to be based on an adjusted analysis.

Although the findings were robust as demonstrated by two different adjusted models yielding the same results, caution is needed when interpreting the study findings due to important limitations. Our sample largely consisted of parent respondents who identified as Caucasian with high levels of education. Additionally, we were reliant on parent report of ASD severity, ID status and medical and psychiatric comorbid diagnoses. Similarly, categorisation of ED visit type was based on parent report, not chart audits. Although we tried to improve accuracy of parent reporting by engaging in regular follow-up, their responses may still be vulnerable to recall bias. Further research combining parent perspectives with administrative health data would be valuable. Finally, our results are based on a small cohort, and replication with a larger sample is warranted. Future work with larger sample sizes would also enable more detailed analyses, such as ED predictors separated by age group as well as by outcome (eg, hospital admission) or ID status.

\section{Similarities and differences to prior research}

The likelihood of ED use in the current study was not related to age, ID status or ASD severity. Previous research on predictors of ED use among individuals with ASD and other populations has shown mixed results with respect to the role of predisposing demographic factors. ${ }^{1-6}$ For instance, some studies report a greater likelihood of ED visits in older individuals with ASD, ${ }^{24}$ but others do not. ${ }^{6}$ Our cohort may be too small to detect these types of patterns, or indeed, they may not be the drivers of such visits when multivariate analyses include a wider combination of variables.

Only one enabling variable predicted ED use while controlling for predisposing and need variables. Parents who reported that their families were experiencing significant distress at baseline reported that their son or daughter was more likely to visit the ED during the study period. Higher rates of family stress are associated with increased ED use among parents of youth with psychiatric conditions ${ }^{36}$ and higher rates of general health service use among parents of youth with ASD. ${ }^{37}$ This is the first study to report an association between family distress and future ED use in the ASD literature.

With respect to clinical need variables, ED use in the previous year was the strongest predictor of ED visits in the year studied. This is similar to other studies that examine $\mathrm{ED}$ use in individuals with $\mathrm{ID}^{38}$ and our previous study that examined ED use in individuals with ASD over a 2-month period. ${ }^{8}$ Reporting two or more negative life events at baseline more than doubled the likelihood that an individual would visit the ED in the follow-up period. This aligns with previous research showing that life events predicted ED visits in individuals with ID. $^{34}$ Individuals with ASD experience a high frequency of negative life events, trauma and greater stress when compared with typically developing peers. ${ }^{39-41}$ These stressors, in turn, are associated with decreases in social functioning ${ }^{39}$ and depression, ${ }^{42}$ which may lead to greater ED use. 
Open Access

Table 2 ORs and $95 \%$ Cls from bivariate and multivariate analyses predicting ED visits among 284 youth and adults with ASD living in Ontario

\begin{tabular}{|c|c|c|c|}
\hline & Bivariate analysis & Significant predictor only +age model & Fully adjusted model \\
\hline & OR $(95 \% \mathrm{Cl})^{*}$ & OR $(95 \% \mathrm{Cl})^{\dagger}$ & OR $\left(95 \% \mathrm{Cl}^{\ddagger}\right.$ \\
\hline \multicolumn{4}{|l|}{ Predisposing } \\
\hline Age (years) & $1.0(1.0$ to 1.1$)$ & $1.0(1.0$ to 1.1$)$ & $1.0(0.9$ to 1.1$)$ \\
\hline \multicolumn{4}{|l|}{ Gender } \\
\hline Female & $1.8(1.0 \text { to } 3.5)^{\S}$ & $1.8(0.9 \text { to } 3.7)^{\S}$ & $1.8(0.9 \text { to } 3.8)^{\S}$ \\
\hline Male & 1.0 & 1.0 & 1.0 \\
\hline SCQ score & $1.0(0.9$ to 1.0$)$ & & $1.0(0.9$ to 1.0$)$ \\
\hline \multicolumn{4}{|l|}{ ID status } \\
\hline ID (mild to profound ID) & 1.0 & & 1.0 \\
\hline No ID & $1.2(0.7$ to 2.1$)$ & & 1.1 (0.5 to 2.3$)$ \\
\hline Missing & $0.5(0.2$ to 1.6$)$ & & $0.5(0.1$ to 1.7$)$ \\
\hline \multicolumn{4}{|l|}{ Enabling } \\
\hline \multicolumn{4}{|l|}{ Parent marital status } \\
\hline Unmarried & 1.4 (0.8 to 2.6$)$ & & $1.2(0.5$ to 2.5$)$ \\
\hline Married/living with partner & 1.0 & & 1.0 \\
\hline \multicolumn{4}{|l|}{ Parent immigrated } \\
\hline Yes & $1.0(0.5$ to 2.0$)$ & & $1.2(0.6$ to 2.6$)$ \\
\hline No & 1.0 & & 1.0 \\
\hline \multicolumn{4}{|l|}{ Parental education } \\
\hline High education & $1.1(0.6$ to 2.1$)$ & & 1.4 (0.6 to 2.9$)$ \\
\hline Low education & 1.0 & & 1.0 \\
\hline \multicolumn{4}{|l|}{ Neighbourhood income } \\
\hline Low & $1.8(0.9 \text { to } 3.3)^{\S}$ & $1.8(0.9 \text { to } 3.8)^{\S}$ & $1.7(0.8 \text { to } 3.6)^{\S}$ \\
\hline High & 1.0 & 1.0 & 1.0 \\
\hline \multicolumn{4}{|l|}{ Daytime activity } \\
\hline Unstructured & $2.0(0.9 \text { to } 4.1)^{\S}$ & 1.1 (0.4 to 2.9$)$ & 1.1 (0.4 to 3.2$)$ \\
\hline Structured & 1.0 & 1.0 & 1.0 \\
\hline \multicolumn{4}{|l|}{ Family distress } \\
\hline Urban-rural residence & $1.4(1.2 \text { to } 1.6)^{\star \star \star}$ & $1.3(1.1 \text { to } 1.5)^{\star *}$ & $1.3(1.1 \text { to } 1.5)^{\star *}$ \\
\hline Urban & 1.0 & 1.0 & 1.0 \\
\hline Rural & $2.3(1.0 \text { to } 5.0)^{\star}$ & $2.0(0.8 \text { to } 4.9)^{\S}$ & $2.1(0.8 \text { to } 5.4)^{\S}$ \\
\hline \multicolumn{4}{|l|}{ Need } \\
\hline \multicolumn{4}{|l|}{ Medical comorbidity } \\
\hline Yes & 1.1 (0.6 to 2.0$)$ & & $0.8(0.4$ to 1.7$)$ \\
\hline No & 1.0 & & 1.0 \\
\hline \multicolumn{4}{|l|}{ Psychiatric comorbidity } \\
\hline Yes & $1.7(1.0 \text { to } 3.1)^{\S}$ & $1.0(0.5$ to 2.0$)$ & $0.9(0.4$ to 1.9$)$ \\
\hline No & 1.0 & 1.0 & 1.0 \\
\hline \multicolumn{4}{|l|}{ On medication } \\
\hline Yes & $2.5(1.3 \text { to } 4.5)^{\star \star}$ & 1.4 (0.7 to 2.9$)$ & $1.6(0.8 \text { to } 3.5)^{\S}$ \\
\hline No & 1.0 & 1.0 & 1.0 \\
\hline \multicolumn{4}{|l|}{ History of aggression } \\
\hline Yes & 1.2 (0.7 to 2.2$)$ & & $0.8(0.4$ to 1.7$)$ \\
\hline No & 1.0 & & 1.0 \\
\hline
\end{tabular}




\begin{tabular}{|c|c|c|c|}
\hline & Bivariate analysis & Significant predictor only +age model & Fully adjusted model \\
\hline & OR $(95 \% \mathrm{Cl})^{*}$ & OR $(95 \% \mathrm{CI})^{\dagger}$ & OR $\left(95 \% \mathrm{CI}^{\ddagger}\right.$ \\
\hline \multicolumn{4}{|c|}{ ED visit in past year } \\
\hline No & 1.0 & 1.0 & 1.0 \\
\hline \multicolumn{4}{|c|}{$2+$ Negative life events } \\
\hline No & 1.0 & 1.0 & 1.0 \\
\hline
\end{tabular}

${ }^{*}$ Derived from single predictor models.

†Derived from a model that included predictors with a p value of 0.20 or lower in the bivariate analysis: age; gender; neighbourhood income, typical day; family distress, urban-rural residence; psychiatric comorbidity; ED visit in past year; 2+ negative life events.

fDerived from a model that included all predictors, $\mathrm{n}=282$ due to missing data.

$\S p<0.20,{ }^{*} p<0.05,{ }^{* *} p<0.01,{ }^{* \star *} p<0.001$.

ASD, autism spectrum disorder; ED, emergency department; ID , intellectual disability; SCQ, Social Communication Questionnaire.

When looking at unique predictors of each of medical and psychiatric ED visits, distinct enabling variables, like low income and living in a rural area, were associated with medical but not psychiatric emergencies. It is well recognised that some healthcare services are less available in rural areas of Ontario. ${ }^{43}$ In the general population, having lower social economic status is strongly correlated with adverse health outcomes. ${ }^{44}$ Neighbourhood income also predicts preventable hospitalisations in adults with ID. ${ }^{45}$ In our study, it may be that individuals with greater financial means and those who live in urban areas are more able to access specialised medical care, and as such may require less ED support. Not surprisingly, a history of aggression uniquely predicted psychiatric but not medical emergencies. This aligns closely with previous work looking at the predictors of psychiatric hospitalisations in children with ASD, which also pinpoint aggression as a strong predictor. ${ }^{46}{ }^{47}$ Interestingly, being from an immigrant family was associated with psychiatric ED use but was not associated with medical ED visits. This begs the question of how well these families are engaged with and proactively accessing mental health services for their sons or daughters. Individuals who have recently immigrated might have less knowledge of the mental healthcare system and resources to effectively find accessible and appropriate community support services for their child with ASD. ${ }^{48}$

\section{Implications}

Our findings replicate what others have reported regarding frequent ED use among individuals with $\mathrm{ASD}^{1-6}$ and identified a combination of enabling and need variables that may be important for targeting preventative community-based supports. For instance, parents who reported higher family distress were more likely to bring their son or daughter to the ED. Caring for a child with ASD can bring many challenges, which persist across the life course. ${ }^{49}$ When parents indicate that they are approaching crisis, this can also signal future emergencies, and community-based clinicians need to proactively help such families. Brief family distress measures can assist clinicians in determining the severity of the crisis state and in the selection of appropriate interventions. ${ }^{30}$ Likewise, family members themselves can be taught to self-monitor their own distress levels and effective methods of seeking help apart from visiting the ED. From a systemic perspective, policy practices need to expand beyond the identified individual with ASD and include family focused care. Community-based services that provide relief to families, such as respite care, can help reduce stress on families and, in turn, reduce emergency service use for individuals with ASD. ${ }^{50}$

It is equally important for community-based service providers to acknowledge the impact of negative life events on individuals with ASD and their families. Yerkey and Wildman ${ }^{51}$ found that primary care physicians improved their identification rates for youth mental health problems using knowledge of negative life events. Increased clinical knowledge of the difficulties many individuals with ASD experience during transitions and provision of appropriate community mental healthcare targeted at building resiliency when exposed to negative life events may alleviate some need for ED services among this population.

Considering the link between previous and future ED visits, effective care plans need to be in place following the first ED visit to help deal with future crises. Clinical practice guidelines for this population ${ }^{52}$ indicate for ED staff to recommend families work with their community care providers to prepare proactive care plans as part of the discharge process. Further, to ensure individuals with ASD receive appropriate care in the ED and potentially negate the need for repeat visits, families can make use of hospital passports and other patient information tools to assist ED staff in better understanding an individual's specific care needs. ${ }^{53}$ 


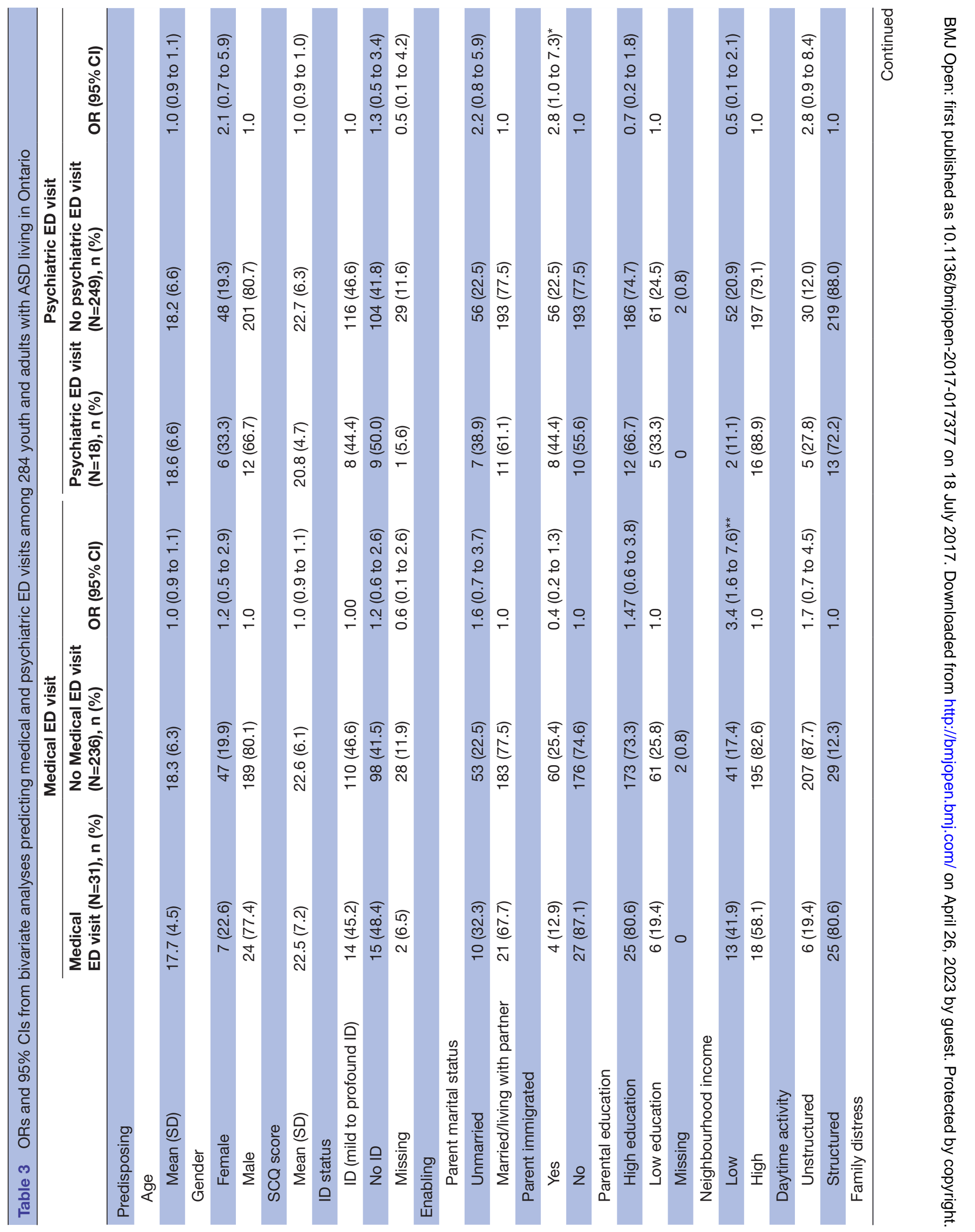




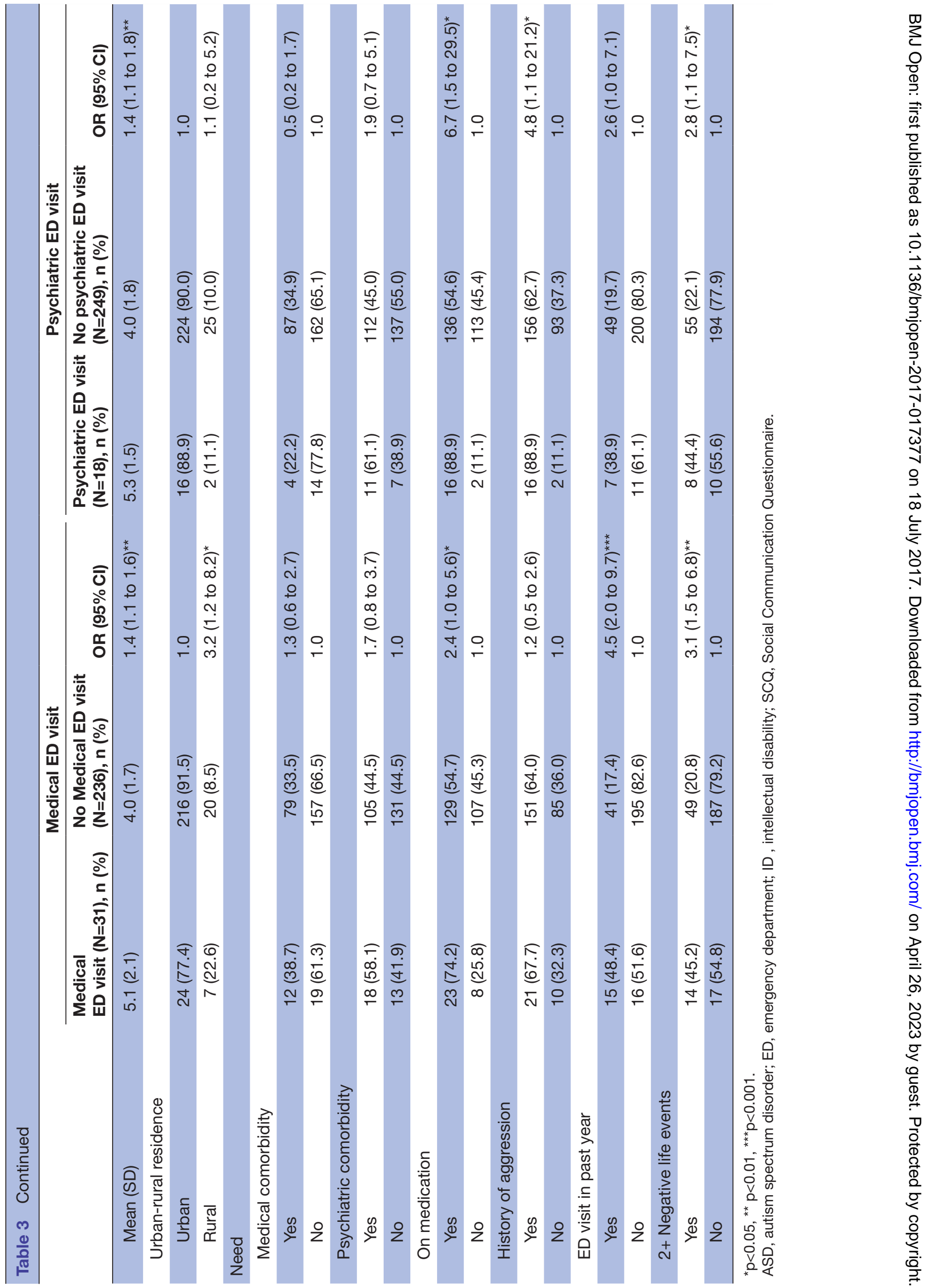


Contributors YL, JAW, AMP and EB were the primary creators of the concept and design of this study. The analytic approach was created by $Y L$ and JAW and carried out by MP-S, AD and AT. YL, MP-S, AD and AT were responsible for drafting the manuscript and integrating all coauthor input. All coauthors contributed substantively to the interpretation of the results and to draft revisions and have approved the final version of the manuscript.

Funding This research was funded by the Canadian Institutes of Health Research (MOP 102677). JAW is supported by the Chair in ASD Treatment and Care Research (Canadian Institutes of Health Research RN162466-284208 in partnership with NeuroDevNet, Sinneave Family Foundation, CASDA, Autism Speaks Canada and Health Canada).

\section{Competing interests None declared.}

Ethics approval Centre for Addiction and Mental Health; York University. Provenance and peer review Not commissioned; externally peer reviewed. Data sharing statement № additional data are available.

Open Access This is an Open Access article distributed in accordance with the Creative Commons Attribution Non Commercial (CC BY-NC 4.0) license, which permits others to distribute, remix, adapt, build upon this work non-commercially, and license their derivative works on different terms, provided the original work is properly cited and the use is non-commercial. See: http://creativecommons.org/ licenses/by-nc/4.0/

C Article author(s) (or their employer(s) unless otherwise stated in the text of the article) 2017. All rights reserved. No commercial use is permitted unless otherwise expressly granted.

\section{REFERENCES}

1. Deavenport-Saman A, Lu Y, Smith K, et al. Do children with autism overutilize the emergency department? Examining visit urgency and subsequent hospital admissions. Matern Child Health $J$ 2016;20:306-14.

2. lannuzzi DA, Cheng ER, Broder-Fingert S, et al. Brief report: emergency department utilization by individuals with autism. $J$ Autism Dev Disord 2015;45:1096-102.

3. Kalb LG, Stuart EA, Freedman B, et al. Psychiatric-related emergency department visits among children with an autism spectrum disorder. Pediatr Emerg Care 2012;28:1269-76.

4. Liu G, Pearl AM, Kong L, et al. A profile on emergency department utilization in adolescents and young adults with autism spectrum disorders. J Autism Dev Disord 2017;47:347-58.

5. Vohra R, Madhavan S, Sambamoorthi U. Emergency department use among adults with autism spectrum disorders (ASD). J Autism Dev Disord 2016;46:1441-54.

6. Schlenz AM, Carpenter LA, Bradley C, et al. Age differences in emergency department visits and inpatient hospitalizations in preadolescent and adolescent youth with autism spectrum disorders. $J$ Autism Dev Disord 2015;45:2382-91.

7. Nicholas DB, Zwaigenbaum L, Muskat B, et al. Toward practice advancement in emergency care for children with autism spectrum disorder. Pediatrics 2016;137 Suppl 2:S205-S211.

8. Lunsky Y, Paquette-Smith M, Weiss JA, et al. Predictors of emergency service use in adolescents and adults with autism spectrum disorder living with family. Emerg Med J 2015;32:787-92.

9. McGonigle JJ, Migyanka JM, Glor-Scheib SJ, et al. Development and evaluation of educational materials for pre-hospital and emergency department personnel on the care of patients with autism spectrum disorder. J Autism Dev Disord 2014;44:1252-9.

10. Nicholas DB, Zwaigenbaum L, Muskat B, et al. Experiences of emergency department care from the perspective of families in which a child has autism spectrum disorder. Soc Work Health Care 2016:55:409-26.

11. Pines JM, Hilton JA, Weber EJ, et al. International perspectives on emergency department crowding. Acad Emerg Med 2011;18:1358-70.

12. Tang N, Stein J, Hsia RY, et al. Trends and characteristics of US emergency department visits, 1997-2007. JAMA 2010;304:664-70.

13. Croen LA, Zerbo O, Qian Y, et al. The health status of adults on the autism spectrum. Autism 2015;19:814-23.

14. Levy SE, Giarelli E, Lee LC, et al. Autism spectrum disorder and cooccurring developmental, psychiatric, and medical conditions among children in multiple populations of the United States. J Dev Behav Pediatr 2010;31:267-75.
15. Anderson C, Law JK, Daniels A, et al. Occurrence and family impact of elopement in children with autism spectrum disorders. Pediatrics 2012;130:870-7.

16. Matson JL, Rivet $\Pi$. Characteristics of challenging behaviours in adults with autistic disorder, PDD-NOS, and intellectual disability. $J$ Intellect Dev Disabil 2008;33:323-9.

17. Mazurek MO, Kanne SM, Wodka EL. Physical aggression in children and adolescents with autism spectrum disorders. Res Autism Spectr Disord 2013;7:455-65.

18. Cohen-Silver JH, Muskat B, Ratnapalan S. Autism in the emergency department. Clin Pediatr 2014;53:1134-8.

19. Wang LW, Tancredi DJ, Thomas DW. The prevalence of gastrointestinal problems in children across the United States with autism spectrum disorders from families with multiple affected members. J Dev Behav Pediatr 2011;32:351-60.

20. Kalb LG, Vasa RA, Ballard ED, et al. Epidemiology of injury-related emergency department visits in the US among youth with autism spectrum disorder. J Autism Dev Disord 2016;46:2756-63.

21. Lee LC, Harrington RA, Chang JJ, et al. Increased risk of injury in children with developmental disabilities. Res Dev Disabil 2008;29:247-55.

22. Schlenz AM, Carpenter LA, Bradley C, et al. Age differences in emergency department visits and inpatient hospitalizations in preadolescent and adolescent youth with autism spectrum disorders. J Autism Dev Disord 2015;45:2382-91.

23. Isaksen J, Bryn V, Diseth TH, et al. Children with autism spectrum disorders - the importance of medical investigations. Eur $\mathrm{J}$ Paediatr Neurol 2013;17:68-76.

24. Minshawi NF, Hurwitz S, Morriss D, et al. Multidisciplinary assessment and treatment of self-injurious behavior in autism spectrum disorder and intellectual disability: integration of psychological and biological theory and approach. J Autism Dev Disord 2015;45:1541-68.

25. Andersen RM. Revisiting the behavioral model and access to medical care: does it matter? J Health Soc Behav 1995;36:1-10.

26. Rutter M, Bailey A, Lord C. 2003. The Social Communication Questionnaire: Manual: Western Psychological Services.

27. Brooks WT, Benson BA. The validity of the Social Communication Questionnaire in adults with intellectual disability. Res Autism Spectr Disord 2013;7:247-55

28. Statistics Canada. Census forward sortation area. Ottawa, ON, Canada: Geography Division, 2006.

29. Statistics Canada. From urban areas to population centres. http:// www.statcan.gc.ca/eng/subjects/standard/sgc/notice/sgc-06. (accessed 3 Aug 2016).

30. Weiss JA, Lunsky Y. The Brief Family Distress Scale: a measure of crisis in caregivers of individuals with autism spectrum disorders. $J$ Child Fam Stud 2011;20:521-8.

31. Gurney JG, McPheeters ML, Davis MM. Parental report of health conditions and health care use among children with and without autism: National Survey of Children's Health. Arch Pediatr Adolesc Med 2006;160:825-30.

32. Montes G, Halterman JS. Psychological functioning and coping among mothers of children with autism: A population-based study. Pediatrics 2007:119:e1040-e1046.

33. Moss S, Patel P, Prosser H, et al. Psychiatric morbidity in older people with moderate and severe learning disability. I: development and reliability of the patient interview (PAS-ADD). Br J Psychiatry 1993;163:471-80.

34. Lunsky Y, Elserafi J. Life events and emergency department visits in response to crisis in individuals with intellectual disabilities. $J$ Intellect Disabil Res 2011:55:714-8.

35. Hastings RP, Hatton C, Taylor JL, et al. Life events and psychiatric symptoms in adults with intellectual disabilities. $J$ Intellect Disabil Res 2004;48:42-6.

36. Chavira DA, Garland A, Yeh M, et al. Child anxiety disorders in public systems of care: comorbidity and service utilization. J Behav Health Serv Res 2009;36:492-504.

37. Thomas KC, Ellis AR, McLaurin C, et al. Access to care for autismrelated services. J Autism Dev Disord 2007;37:1902-12.

38. Lunsky Y, Balogh R, Cairney J. Predictors of emergency department visits by persons with intellectual disability experiencing a psychiatric crisis. Psychiatr Serv 2012;63:287-90.

39. Bishop-Fitzpatrick L, Mazefsky CA, Minshew NJ, et al. The relationship between stress and social functioning in adults with autism spectrum disorder and without intellectual disability. Autism Res 2015;8:164-73.

40. Hoover DW. The effects of psychological trauma on children with autism spectrum disorders: a research review. Review Journal of Autism and Developmental Disorders 2015;2:287-99. 
41. Spratt EG, Nicholas JS, Brady KT, et al. Enhanced cortisol response to stress in children in autism. J Autism Dev Disord 2012;42:75-81.

42. Fung S, Lunsky Y, Weiss JA. Depression in youth with autism spectrum disorder: the role of ASD vulnerabilities and family? Environmental stressors. J Ment Health Res Intellect Disabil 2015;8:120-39.

43. Glazier RH, Tepper J, Agha MM, et al. Primary care in disadvantaged populations. Primary care in Ontario: ICES atlas . Institute for Clinical Evaluative Sciences 2006.

44. Pickett KE, Wilkinson RG. Income inequality and health: a causal review. Soc Sci Med 2015;128:316-26.

45. Balogh RS, Ouellette-Kuntz $\mathrm{H}$, Brownell $\mathrm{M}$, et al. Factors associated with hospitalisations for ambulatory care-sensitive conditions among persons with an intellectual disability: a publicly insured population perspective. J Intellect Disabil Res 2013;57:226-39.

46. Mandell DS. Psychiatric hospitalization among children with autism spectrum disorders. J Autism Dev Disord 2008;38:1059-65.

47. Stark KH, Barnes JC, Young ND, et al. Brief report: understanding crisis behaviors in hospitalized psychiatric patients with autism spectrum disorder-iceberg assessment interview. J Autism Dev Disord 2015;45:3468-74.

48. Weiss JA, Tint A, Paquette-Smith M, et al. Perceived self-efficacy in parents of adolescents and adults with autism spectrum disorder. Autism 2016;20:425-34.

49. Lounds J, Seltzer MM, Greenberg JS, et al. Transition and change in adolescents and young adults with autism: longitudinal effects on maternal well-being. Am J Ment Retard 2007;112:401-17.

50. Mandell DS, Xie M, Morales KH, et al. The interplay of outpatient services and psychiatric hospitalization among medicaid-enrolled children with autism spectrum disorders. Arch Pediatr Adolesc Med 2012;166:68-73.

51. Yerkey TM, Wildman BG. Use of information about maternal distress and negative life events to facilitate identification of psychosocial problems in children. Fam Pract 2004;21:261-5.

52. Sullivan WF, Heng J, Cameron D, et al. Consensus guidelines for primary health care of adults with developmental disabilities. Can Fam Physician 2006;52:1410-8.

53. Venkat A, Migyanka JM, Cramer R, et al. An instrument to prepare for acute care of the individual with autism spectrum disorder in the emergency department. J Autism Dev Disord 2016;46:2565-9. 